\title{
The trigger to cell death determines the efficiency with which dying cells are cleared by neighbours
}

\author{
UK Wiegand ${ }^{1,4}$, S Corbach $^{1}$, AR Prescott ${ }^{2}$, J Savill $^{3}$ and \\ BA Spruce ${ }^{\star, 1,5}$ \\ 1 Department of Anatomy and Physiology, MSI/WTB, University of Dundee, Dow \\ Street, Dundee, DD1 5EH, UK \\ 2 Department of Biochemistry, MSI/WTB, University of Dundee, Dow Street, \\ Dundee, DD1 5EH, UK \\ ${ }^{3}$ Centre for Inflammation Research, Department of Clinical and Surgical \\ Sciences (Internal Medicine), Royal Infirmary, Lauriston Place, Edinburgh, \\ EH3 9YW, UK \\ ${ }^{4}$ Current address: Membrane Biology Group, Department of Biomedical \\ Sciences, University of Edinburgh, George Square, Edinburgh, EH8 9XD, UK \\ ${ }^{5}$ Current address: Department of Surgery and Molecular Oncology, Ninewells \\ Hospital and Medical School, Dundee, DD1 9SY, UK \\ * Corresponding author: BA Spruce, Department of Surgery and Molecular \\ Oncology, Ninewells Hospital and Medical School, Dundee, DD1 9SY, UK \\ Tel.: +44 1382496 427; Fax:+44 1382496363 \\ E-mail: b.a.spruce@dundee.ac.uk
}

Received 28.8.00; revised 26.1.01; accepted 28.2.01

Edited by $\mathrm{K}$ Vousden

\begin{abstract}
Phagocytosis of apoptotic cells is required to prevent tissue injury. Professional phagocytes, such as monocyte-derived macrophages, are highly efficient scavengers of apoptotic cells but their presence cannot always be relied on; in that case, removal of effete cells is accomplished by helpful neighbours. This study describes differences in the efficiency with which apoptotic cells of the same type, but dying in response to different triggers, are engulfed; this varies from engulfment that is so proficient few or no unengulfed apoptotic cells are found, to engulfment that is so delayed apoptotic cells have become secondarily necrotic at the point of engulfment. In all cases the efficiency of engulfment is determined at least in part by the dying cells themselves. p53and Bax-transfected kidney epithelial (293) cells (transiently transfected using a non-toxic method) were engulfed so proficiently by homotypic neighbours that cells did not show evidence of engagement of the apoptotic programme (chromatin condensation and TUNEL positivity) until engulfment had taken place. Engulfment nonetheless required activation of at least initiator caspases. 293 cells induced to apoptose by other means (etoposide and staurosporine treatment) were not so efficiently ingested: unengulfed apoptotic cells were consistently revealed at all doses and time points, even when treated cells were mixed with healthy, non-treated 293 cells. These data make it extremely unlikely that the fraction of viable, unaffected neighbours determines the efficiency with which engulfment proceeds. Furthermore, 293 cells treated with etoposide or staurosporine were differentially appealing both to homotypic neighbours and
\end{abstract}

to cells in the professional phagocyte lineage (THP-1 cells). If different apoptotic stimuli programme cells to be recognised with different efficiencies, pathways to apoptosis may be injury limiting to greater or lesser degrees. Cell Death and Differentiation (2001) 8, 734-746.

Keywords: apoptosis; phagocytosis; p53; Bax

Abbreviations: CMTMR, 5-(and 6)-(((4-chloromethyl)benzoyl)amino)tetramethylrhodamine; CMFDA, 5-chloromethylfluorescein diacetate; DIC, differential interference contrast; GFP, green fluorescent protein; $\mathrm{PI}$, propidium iodide; PS, phosphatidylserine; TUNEL, terminal deoxynucleotide transferase-mediated dUTPflourescein nick-end labelling; zVAD-fmk, benzyloxycarbonylvalinyl-alanyl-aspartyl-(OMe)-fluoromethyl ketone

\section{Introduction}

If most of our cells are constantly primed to die, ${ }^{1-3}$ a necessary safeguard would be a constantly available means to execute that most crucial end-point in the death process: removal of apoptotic cells by phagocytosis. Inflammation is prevented only if membrane-bound apoptotic bodies are engulfed by dedicated or non-dedicated phagocytes before spillage of noxious intracellular contents occurs; furthermore, phagocytosis of intact apoptotic cells is unaccompanied by the pro-inflammatory cytokine release which occurs when necrotic cell debris is phagocytosed. ${ }^{4,5}$ In vivo, apoptotic cells, which fail to be taken up by phagocytes, undergo secondary necrosis (so-called because of cell swelling and membrane rupture), with its attendant risk of pro-inflammatory consequences. ${ }^{6}$ This was graphically illustrated when agonistic Fas antibodies administered to mice induced massive hepatic apoptosis which outstripped phagocytic capability; secondary hepatic necrosis and death of the animals ensued as a consequence. ${ }^{7}$

The importance of bystander-mediated phagocytosis is underlined in the organism $C$. elegans which lacks dedicated phagocytes; yet there are several genes which are required for the engulfment of cell corpses. ${ }^{8-11}$ In higher organisms, phagocytosis is accomplished by professional phagocytes of the macrophage lineage but when these are not available, surrogates of many types can fulfil the role: epithelia, ${ }^{12}$ endothelia, ${ }^{13,14}$ glomerular mesangial cells, ${ }^{15,16}$ fibroblasts ${ }^{17}$ and tumour cells ${ }^{6}$ are all capable of phagocytic ingestion of apoptotic cells of the same or different types. It has been suggested that most cell types could possess the ability to phagocytose apoptotic cells in vivo, ${ }^{4}$ a strategy to cope with the existence of a latent core death program in the vast majority of cells.

A multiplicity of ways in which phagocytes recognise and then engulf apoptotic cells suggests that a hierarchy of engulfment mechanisms and back-ups may exist; these mechanisms have been best characterised in professional 
A

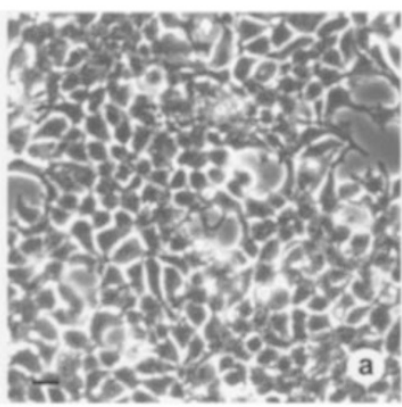

vector

B

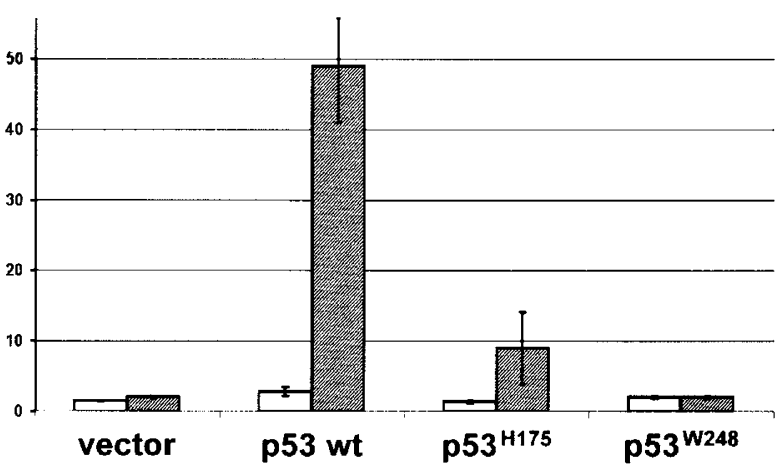

口\% sub G0/G1 cells phagocytes $/ 1000$ cells

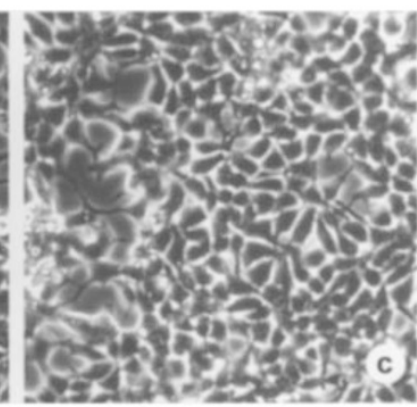

p53 mutant H175

C

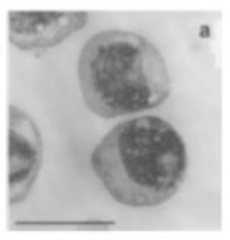

vector

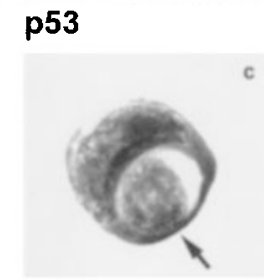

p53

D
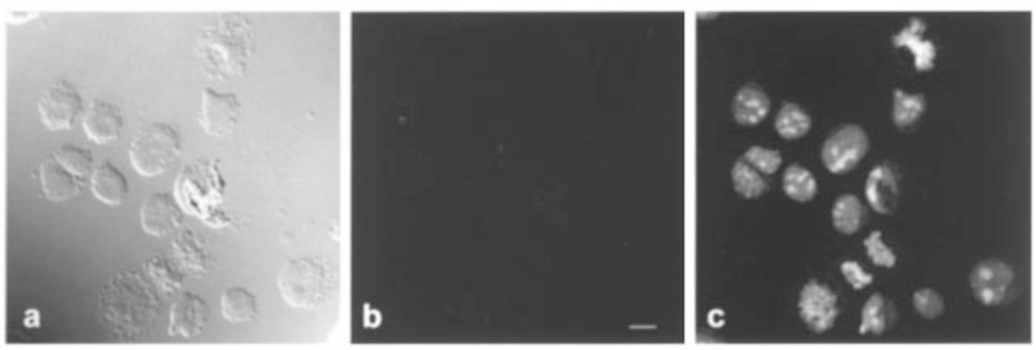

vector

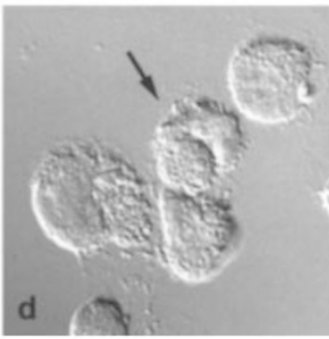

DIC

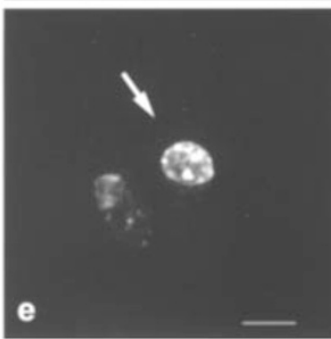

TUNEL

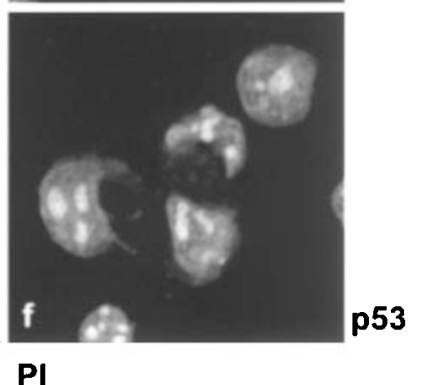

Figure 1 Overexpressed wild-type, but not mutant p53, induces phagocytosis in 293 cells. 293 cells were transiently transfected as described in Materials and Methods with parent vector, or vectors encoding p53, p53 ${ }^{\mathrm{H} 175}$, or p53 ${ }^{\mathrm{W} 248}$. (A) Phase contrast micrographs taken $48 \mathrm{~h}$ post-transfection. Arrowheads in panel $\mathbf{b}$ indicate areas of cell 'clustering'. Bar, $20 \mu \mathrm{m}$. (B) $48 \mathrm{~h}$ after transfection cells were processed for apoptosis and phagocytosis assay as described in Materials and Methods. Apoptotic cell numbers (cells with sub-normal DNA content) are expressed as a percentage of the total cell population (sample size: $n=20000$ ). Mean percentage values from at least three different experiments in triplicate are given ( \pm S.E.M.; open bars). Phagocytes were scored by counting cells containing one or more phagosomes (sample size of at least 2000 cells for each value) by brightfield microscopy; phagocyte numbers are expressed as a fraction of 1000 sample cells. The data represent the average of at least three independent experiments in triplicate ( + S.E.M.; hatched bars). (C) A representative micrograph of a histochemically stained phagocyte containing an apoptotic body is shown in panel $\mathbf{b}$, whereas panel $\mathbf{c}$ illustrates a phagosome containing a cell that appears to be morphologically normal. Bar, $10 \mu \mathrm{m}$. (D) Confocal micrographs of control (upper row) and p53-transfected (lower row) 293 cells, labelled by the TUNEL procedure to detect DNA strand breaks and with propidium iodide (PI) to locate cell nuclei. Arrows depict an engulfed TUNEL positive cell. Bars, $10 \mu \mathrm{m}$ 
phagocytes but understanding remains incomplete even in these cells. What is known is that apoptotic cells undergo surface changes which mark them for recognition and subsequent engulfment by phagocytes; these markers of edibility include carbohydrate changes, ${ }^{18}$ exposure of phosphatidylserine (PS $)^{19-21}$ and the adhesion molecule ICAM-3 (in B cells ${ }^{22,23}$ ). A number of cell surface molecules on phagocytes have also been implicated in apoptotic cell recognition and engulfment although, disappointingly, cognate apoptotic ligand-phagocyte receptor partnerships remain to be defined. Phagocyte cell surface 'receptors' for apoptotic cells include the $\alpha_{v} \beta_{3}$ vitronectin receptor; ${ }^{24,25}$ CD36, which may bind (in concert with $\alpha_{v} \beta_{3}$ ) secreted thrombospondin-1, a putative bridge to the apoptotic cell, ${ }^{26,27}$ the Class A scavenger receptor, ${ }^{28}$ the ATPbinding cassette transporter $A B C-1,{ }^{29-31}$ macrophage CD14, ${ }^{32}$ and putative receptors for complement components since $\mathrm{C} 1 \mathrm{q}$ binds apoptotic cells ${ }^{33}$ and $\mathrm{C} 1 \mathrm{q}$ deficient mice exhibit defective apoptotic cell clearance, ${ }^{34}$ and a receptor which appears to recognise PS. ${ }^{35}$

The mechanisms which underlie amateur phagocytosis have been much less studied but the evidence so far is that they may be similar: for example, the vitronectin receptor is involved in fibroblast-mediated engulfment of apoptotic neutrophils, ${ }^{17}$ and the $C$. elegans engulfment gene, ced-7, encodes an $\mathrm{ABC}$ transporter homologue which functions in both dying and engulfing cells. ${ }^{11}$

The uptake of an apoptotic cell by a phagocyte has previously been regarded as a fortuitous event, its success or failure being determined only by phagocyte availability and innate engulfment capability of the phagocyte involved. Yet in this study we show that the swiftness with which apoptotic cells are engulfed varies according to the trigger to death. In one extreme manifestation, p53 and Baxtransfected cells were so appealing to their neighbours that they were ingested before evidence that apoptosis had been engaged. High proficiency engulfment of apoptotic cells would discourage secondary necrosis and have greater injury-limiting potential in vivo.

\section{Results}

\section{Overexpressed wild-type, but not mutant, p53 is associated with high proficiency engulfment of apoptotic cells}

In the course of studies to investigate the function of the p53 protein, we transiently overexpressed p53 within 293 , human embryonic kidney epithelial cells, to mimic activation of the p53 response. Phase microscopy (Figure 1A) revealed clustering (as indicated by arrows) and apparent disappearance of 293 cells transiently transfected with wild-type p53. Transfection efficiencies, scored using green fluorescent protein as a reporter, were consistently high (mean $32.4 \%, \pm 7.5 \%$ S.E.M.); yet there was little or no increase in the number of free apoptotic cells in the culture. Apoptotic cell scores were determined by flow cytometric analysis of permeabilised, propidium iodide stained cells which when apoptotic have an apparently subnormal DNA content (visible as a sub-G1 peak; Figure 1B, unfilled bars).
Despite the apparent absence of death in the unengulfed cell fraction, numbers of phagocytes (cells containing one or more engulfed bodies within phagosomes; Figure 1B hatched bars) were more than 10-fold higher in p53transfected cells, compared to cells transfected with the control vector. Microscopic assessment and quantitation of histochemically-stained cells revealed that the vast majority (98.9\% $\pm 5 \%$ S.E.M.) of engulfed cells inside phagosomes appeared apoptotic (Figure 1C, panel b, see arrows); apoptotic engagement in engulfed cells was confirmed by TUNEL staining, in this case by confocal microscopy which also confirmed the intracellular location of the apoptotic bodies (Figure 1D, panels $d$ and e). Thus, overexpressed p53 drives 293 cells to be phagocytosed so efficiently that dying cells are engulfed very early in the death program and no increase in free apoptotic cells above control values is observed; this also illustrates the limitation of scoring apoptosis by measurement of cellular DNA content using flow cytometric analysis of propidium iodide stained cells, a method which will only detect unengulfed 'free' apoptotic cells.

Interestingly, following p53 transfection, a small percentage $(1.1 \pm 0.05 \%$ S.E.M.) of engulfed cells appeared viable (Figure 1C, panel $\mathrm{c}$ ). We presume that such cells had undergone membrane changes, which marked them for recognition and engulfment. This prompted us to examine p53-transfected cells-that had not yet been engulfed-for permeability to Hoechst 33342 in case apparently viable cells had undergone membrane permeability changes concomitant with surface changes which mark them for recognition and engulfment. However, Hoechst 33342 staining of p53-transfected cells was negative (data not shown); thus, surface membrane changes which marked the cells for early engulfment must have preceded changes in membrane permeability which would mediate access of Hoechst to the nucleus.

To determine whether mutant p53 which is defective in tumour suppressor function may have retained phagocytic function, we transiently overexpressed (expression was confirmed by immunostaining) two human tumour-associated p53 point mutants-p53 $3^{\mathrm{H} 175}$ and $\mathrm{p} 53^{\mathrm{W} 248}-$ in 293 cells; in both cases, no significant induction of phagocytosis or death was observed (Figure 1B, unfilled and hatched bars). Thus, we provisionally conclude that the so-called core DNA binding domain of the p53 protein is required for both phagocytosis and death induction.

\section{p53 is not sufficient to promote efficient engulfment}

To determine whether overexpressed p53 might be sufficient to promote early engulfment in other cell types, we examined phagocytosis induction in a human osteosarcoma cell line in which p53 is driven by a tetracycline inducible promoter (Saos-2::p53 ${ }^{\text {teti }}$ ). In the presence of increasing concentrations of the tetracycline analogue, doxycycline, apoptosis was induced (Figure 2A, unfilled bars); yet, there was no induction of phagocytosis (Figure 2A, hatched bars). Phase contrast microscopic assessment (Figure $2 \mathrm{~B}$ ) revealed cells with a typical apoptotic appearance (shrunken, detached and 
blebbing) at higher doses of doxycycline (Figure 2B, panel c). Overexpressed p53 is therefore in itself not sufficient to drive phagocytosis in concert with apoptosis.

To address whether the lack of phagocytosis was due to a defect in engulfing capability of Saos2 cells or a defect in their engulfability, p53-overexpressing Saos2::p53 ${ }^{\text {teti }}$ cells were mixed with healthy 293 cells. Even 293 cells were unable to engulf p53-overexpressing Saos2 cells, suggesting that the defect is due to reduced engulfability of Saos2 cells.

\section{Bax also induces engulfment, which keeps pace with Bax-induced apoptosis in 293 cells}

293 cells express protein products of the E1B gene, which have an inhibitory effect on p53-dependent apoptosis. ${ }^{36} \mathrm{We}$ speculated therefore that apoptosis induced by overexpressed p53 in 293 cells may be inefficient and somehow atypical due to modulation by E1B. The pro-apoptotic mediator Bax disrupts the interaction between $\mathrm{Bcl}-\mathrm{X}_{\mathrm{L}}$ and Apaf- $1,{ }^{37}$ which will lead to caspase activation. Bax has also been deduced to displace ced-4 (Apaf-1 homologue in C. elegans) from the E1B $19 \mathrm{~K}$ protein. ${ }^{38}$ Another model is that Bax directly induces release of cytochrome $c$ from isolated mitochondria ${ }^{39}$ and from mitochondria in intact cells including cerebellar granule neurons due to Bid-mediated alteration in Bax conformation. ${ }^{40}$ Together, these findings indicate that $\mathrm{Bax}$ is competent to override a brake on apoptosis and caspase activation resulting from E1B overexpression. Importantly, this would address whether a transfected gene, which is more competent to induce apoptosis in the presence of E1B, is still able to induce high proficiency engulfment.

Transiently overexpressed Bax was consistently associated with a greater degree of phagocytosis than had been observed with p53 (Figure 3A, hatched bars: approximately $15 \%$ of total cells compared to $5 \%$ in p53-transfected cells as in Figure 1B); again, the vast majority (more than 98\%) of engulfed cells appeared apoptotic (Figure 3B, panels $\mathrm{C}$ and $\mathrm{d}$, and Figure $3 \mathrm{C}$, panel $\mathrm{f}$; cells indicated by arrows show engulfed apoptotic bodies) and were TUNEL positive (Figure 3C, panel e). This would be consistent with Bax acting as a more potent inducer of apoptosis in 293 cells than p53 due to independence from restraint imposed by E1B. Despite this more potent stimulus to apoptosis induction, no increase in unengulfed apoptotic cells was observed. Therefore, as with p53, Bax promoted engulfment, which was perfectly in pace with apoptosis induction so that no rise in free apoptotic cells was detectable by flow cytometric analysis (Figure 3A, unfilled bars). Hoechst 33342 staining of Bax-transfected cells was negative, suggestive, as with p53, that surface membrane changes precede permeability changes.

Apoptosis is never a synchronous process even in a clonal population of cells and therefore a wave of apoptosis followed by a wave of phagocytosis would not be expected to occur; nonetheless, to exclude a time-dependent effect, cells were examined at earlier times on a number of occasions (see for example Figure 4B showing apoptotic scores at 24 and $48 \mathrm{~h}$-unfilled and solid bars respec- tively-after Bax transfection); even at earlier times, apoptosis was no higher than in control transfected cell populations, which indicates that engulfment had occurred exceptionally early in the apoptotic program. Despite this, TUNEL positive apoptotic bodies were present inside phagosomes (Figure $3 \mathrm{C}$ ); this indicates that the apoptotic program proceeds within the phagosome.

It is interesting to note however that p53 and Baxoverexpressing cells exhibited high proficiency engulfment only when transfected using 'non-toxic' transfection methods such as lipid-mediated transfection; in contrast, when calcium phosphate transfection methods were used, phagocytosis consistently failed to keep pace with apoptosis such that free apoptotic cells were consistently revealed (data not shown). This suggests that cellular stress can modulate the response.

\section{Bax and p53 provide a drive to the apoptotic cell to enhance its engulfability}

A drive to engulfment could conceivably arise either from an increase in engulfing ability of the phagocyte or an increase in engulfability ('edibility') of the apoptotic cell. To address this in a homotypic system, we marked Bax or p53-transfected 293 cells by co-expression of green fluorescent protein (GFP) and co-stained with phalloidin to label the actin cytoskeleton of transfected and non-transfected cells (Figure 4A; representative confocal micrographs). Phalloidin staining revealed the presence of typical $F$-actin rings surrounding phagosomes (as in Figure 4A, panels e and $\mathrm{h}$, indicated by arrowheads). GFPexpressing cells, when Bax or p53 was co-expressed, were engulfed with equal efficiency by transfected and nontransfected neighbours. In contrast, non-transfected cells were virtually never engulfed. This suggested that apoptotic cell-intrinsic features were responsible for the drive to enhanced engulfment. Furthermore, the retention of GFP (a non-anchored cytosolic molecule) by the engulfed apoptotic bodies corroborated the absence of Hoechst 33342 staining; this supported the conclusion that engulfment had occurred before an increase in membrane permeability.

It remained possible however that the transfection procedure might have caused a concomitant increase in engulfment potential even in non-overexpressing cells; furthermore, lower levels of overexpressed, microscopically undetectable, Bax or p53 might have still been required in the engulfing cell population. Thus, to definitively confirm that the apoptotic cells themselves were sufficient to provide a drive to enhanced engulfment, 293 cells were co-transfected with GFP and p53 or Bax, then mixed with healthy, orange tracker dye-labelled 293 cells $24 \mathrm{~h}$ post-transfection; cells were harvested $24 \mathrm{~h}$ later for phagocytic analysis. As in the 'unmixed' experiment, where all cells had been subjected to the transfection procedure, approximately $70 \%$ of Bax-transfected cells had been engulfed by transfected and non-transfected cells (Figure 4B, hatched bars; this compared with approximately $15 \%$ of p53-transfected cells). At the time at which the two cell populations were mixed $(24 \mathrm{~h})$, apoptotic cells were no more prevalent in control compared to transfected cell populations (determined by flow cytometric analysis; Figure 

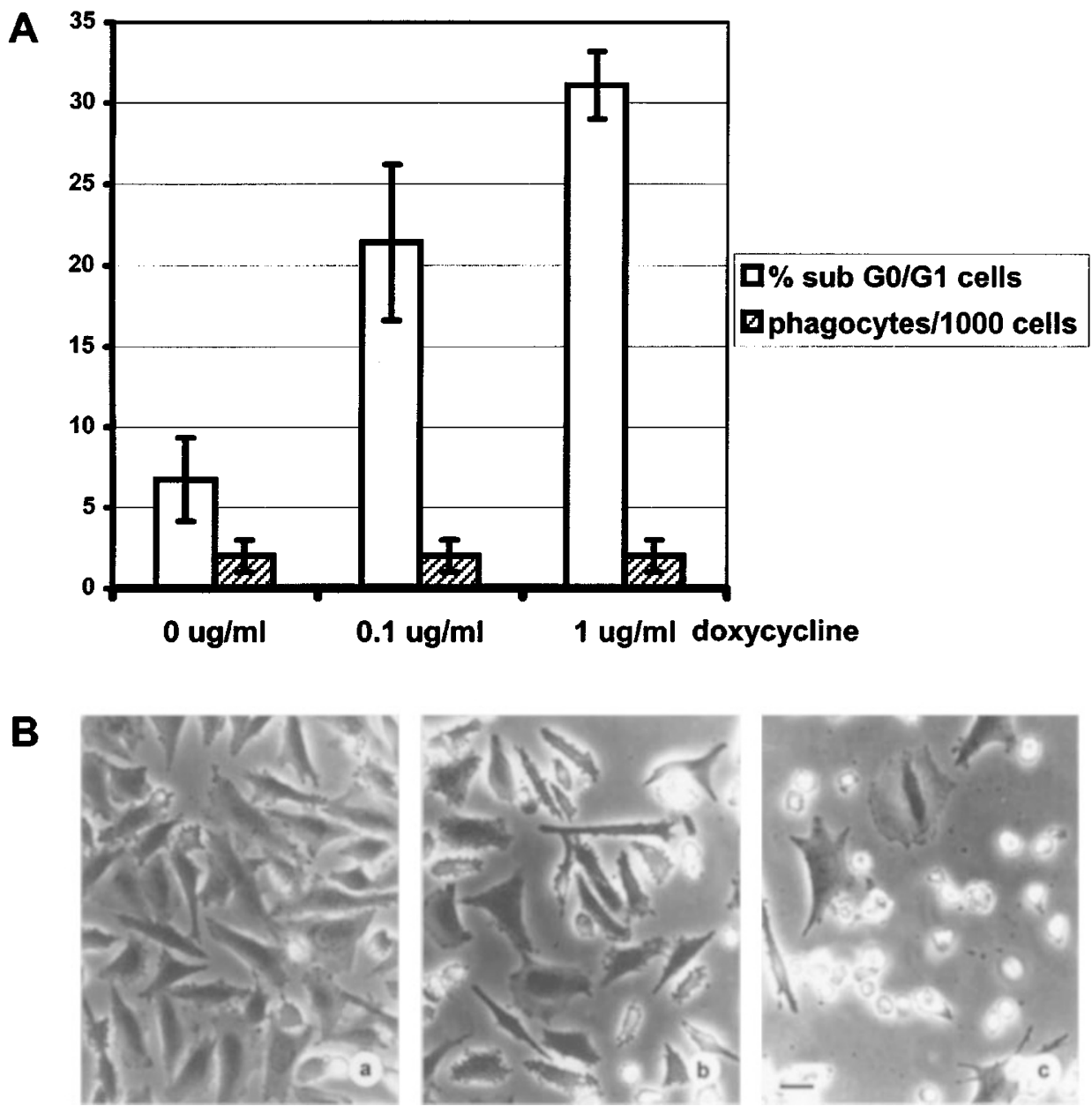

Figure 2 Induction of apoptosis in Saos2::p53 ${ }^{\text {teti }}$ cells does not stimulate phagocytosis. The osteosarcoma Saos2 cell line in its wild-type state has no functional p53, but in this case has been stably transfected with a tetracycline-inducible cDNA construct encoding p53. p53 expression was induced by incubation in medium containing the tetracycline-analogue doxycycline for $48 \mathrm{~h}$. (A) Subsequently, cells were harvested by trypsinisation and processed for flow cytometry as described in Materials and Methods. The percentage of apoptotic cells was assessed by flow cytometry as described in Materials and Methods. Apoptotic cells are expressed as a percentage of the total cell population $(n=20000)$. Mean percentage values of three separate experiments $(+$ S.E.M. $)$ are given. For the phagocytosis assay, cells were prepared, stained and scored as described in Figure 1. Phagocytic scores were obtained by counting at least 1000 cells per sample using brightfield microscopy. The data represent the average from three independent experiments ( \pm S.E.M.). (B) Phase contrast micrographs of cells exposed to increasing concentrations of doxycycline (panel $\mathbf{a}, 0 \mu \mathrm{g} / \mathrm{ml} ; \mathbf{b}, 0.1 \mu \mathrm{g} / \mathrm{ml} ; \mathbf{c}, 1 \mu \mathrm{g} / \mathrm{ml}$ ). Induction of apoptosis leads to free apoptotic cells as shown in panels $\mathbf{b}$ and $\mathbf{c}$ but no evidence of phagocytosis. Bar, $10 \mu \mathrm{m}$

$4 \mathrm{~B}$, unfilled bars); at $48 \mathrm{~h}$ there was still no increase in free apoptotic cells, even in Bax-transfected populations (Figure 4B, filled bars). This highlights that apoptotic cells were efficiently removed at all times.

The apparently extremely high proficiency with which Bax induced internalisation of cells in which it was expressed may have been due in part to slower degradation of the GFP-expressing cell within the phagosome. However, this was excluded by the observation that numbers of GFP-expressing cells had declined by approximately $70 \%$, compared to control GFP-transfected cells, $48 \mathrm{~h}$ after Bax transfection; this compared to a decline of only $10 \%$ approximately, when p53 was expressed (Figure 4C). Thus, Bax may not only promote the early uptake of apoptotic cells but may also accelerate the breakdown of the apoptotic cell within the phagosome.

\section{Bax-driven engulfment requires caspase activation}

A recent paper has described dissociation of apoptotic cell membrane changes from caspase activation. ${ }^{41}$ We were therefore interested to address whether caspase blockade might block Bax-dependent death but preserve engulfment. Bax and GFP co-transfected 293 cells were treated with $100 \mu \mathrm{M}$ ZVAD-fmk (Benzyloxycarbonyl-valinyl-alanyl-aspartyl- (OMe)-fluoromethyl ketone) a broad spectrum cell permeable caspase inhibitor. In the presence of ZVAD-fmk, transfected cell engulfment declined from approximately $60 \%$ to control levels of approximately 5\% (Figure 5, hatched bars); free apoptotic cells remained at very low levels in the presence of ZVAD-fmk (Figure 5, unfilled bars). This indicates that caspases are required for Bax-enhanced engulfment. 
A

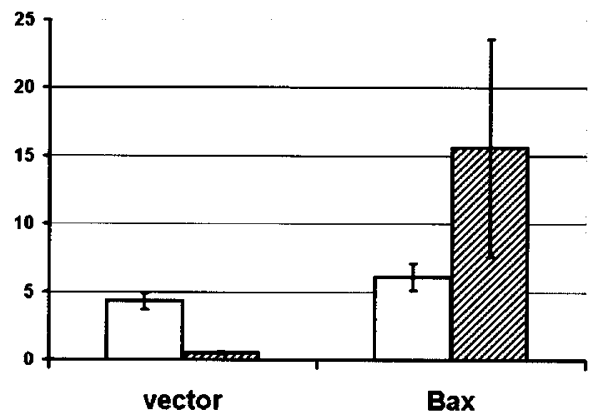

口\% sub G0/G1 cells $\square \%$ phagocytes

\section{B}

Vector
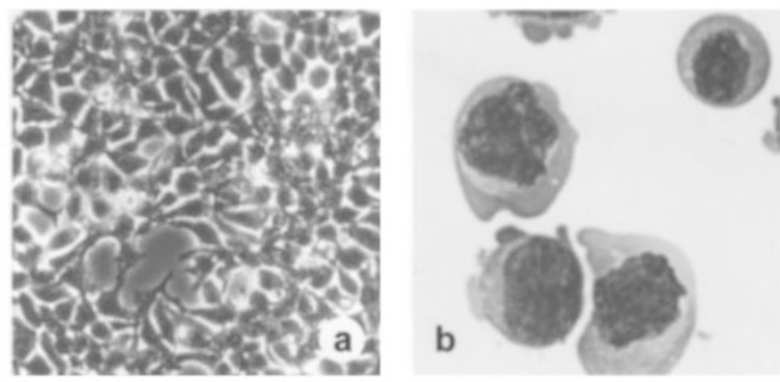

Bax
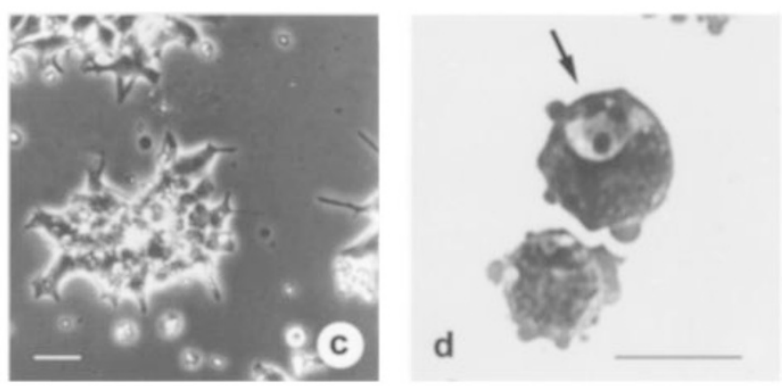

C
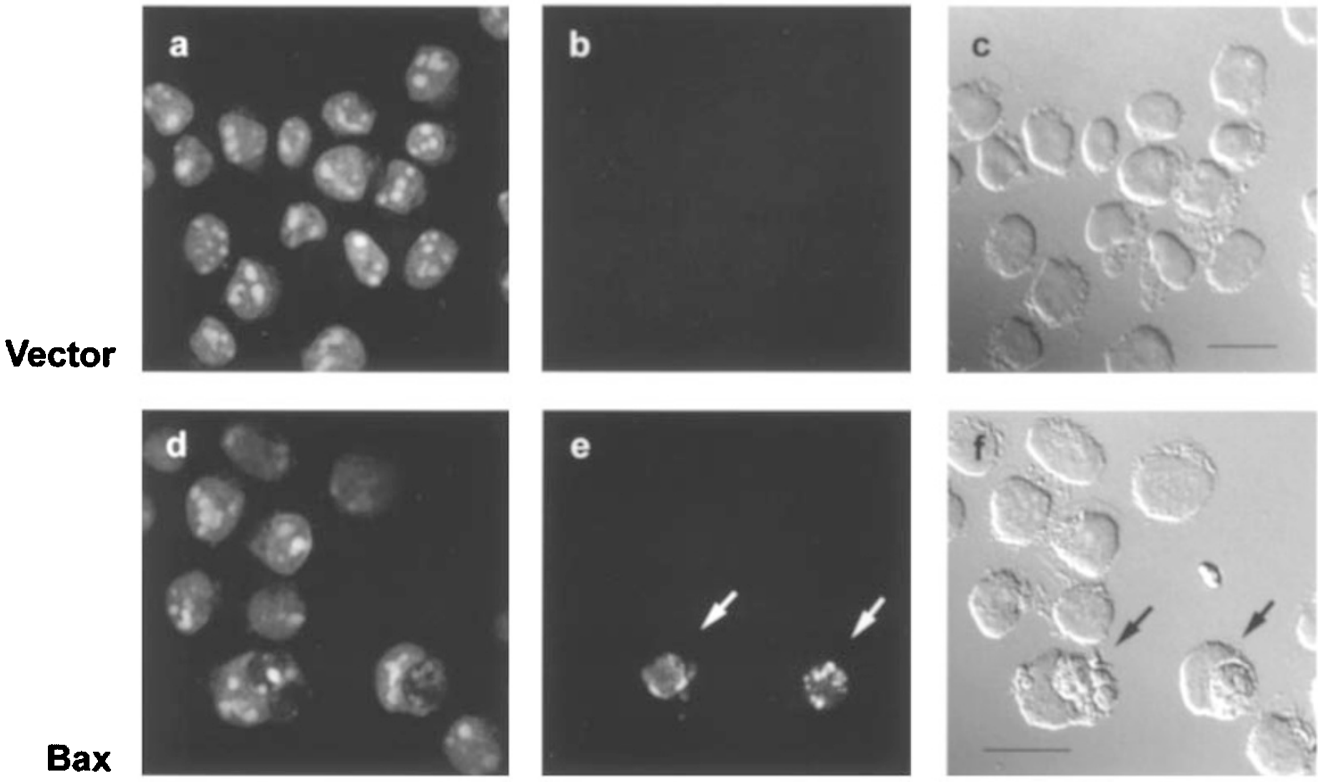

PI

TUNEL

DIC

Figure 3 Transiently overexpressed Bax induces high efficiency clearance of apoptotic 293 cells. 293 cells were transiently transfected with parent vector or Bax encoding vector using a lipid-mediated method (see Materials and Methods). (A) Cells were harvested $48 \mathrm{~h}$ after transfection for assessment of apoptosis and phagocytosis as described in Materials and Methods and Figure 1. Apoptotic cells are expressed as a percentage of total cells (sample size: $n=20000$ ) (open bars). Phagocyte counts were carried out on at least 2000 cells per sample (hatched bars). Mean percentage values from four separate experiments carried out in triplicate ( \pm S.E.M.) are shown. (B) Representative phase contrast micrographs of Bax-transfected and control cells, pre-harvesting, are shown (panels a and c). Bax-transfected cells (panel $\mathbf{c}$ ) show the typical cell clustering and cleared areas. Panels $\mathbf{b}$ and $\mathbf{d}$ depict examples of histochemically stained cells after cytocentrifugation; a phagosome (see arrow) containing an apoptotic body is shown in panel $\mathbf{d}$. (C) To confirm that engulfed bodies had undergone or were undergoing apoptosis, cells were subjected to TUNEL labelling as described in Materials and Methods. Confocal micrographs show chromatin stained by PI (panels $\mathbf{a}$ and $\mathbf{d}$ ), TUNEL labelled cells (panels $\mathbf{b}$ and $\mathbf{e}$ ), and differential interference contrast images (DIC; panels $\mathbf{c}$ and $\mathbf{f}$ ). TUNEL-stained bodies are indicated by arrows in panel e and the corresponding phagocytes in panel f. Bars, $10 \mu \mathrm{m}$ 
A
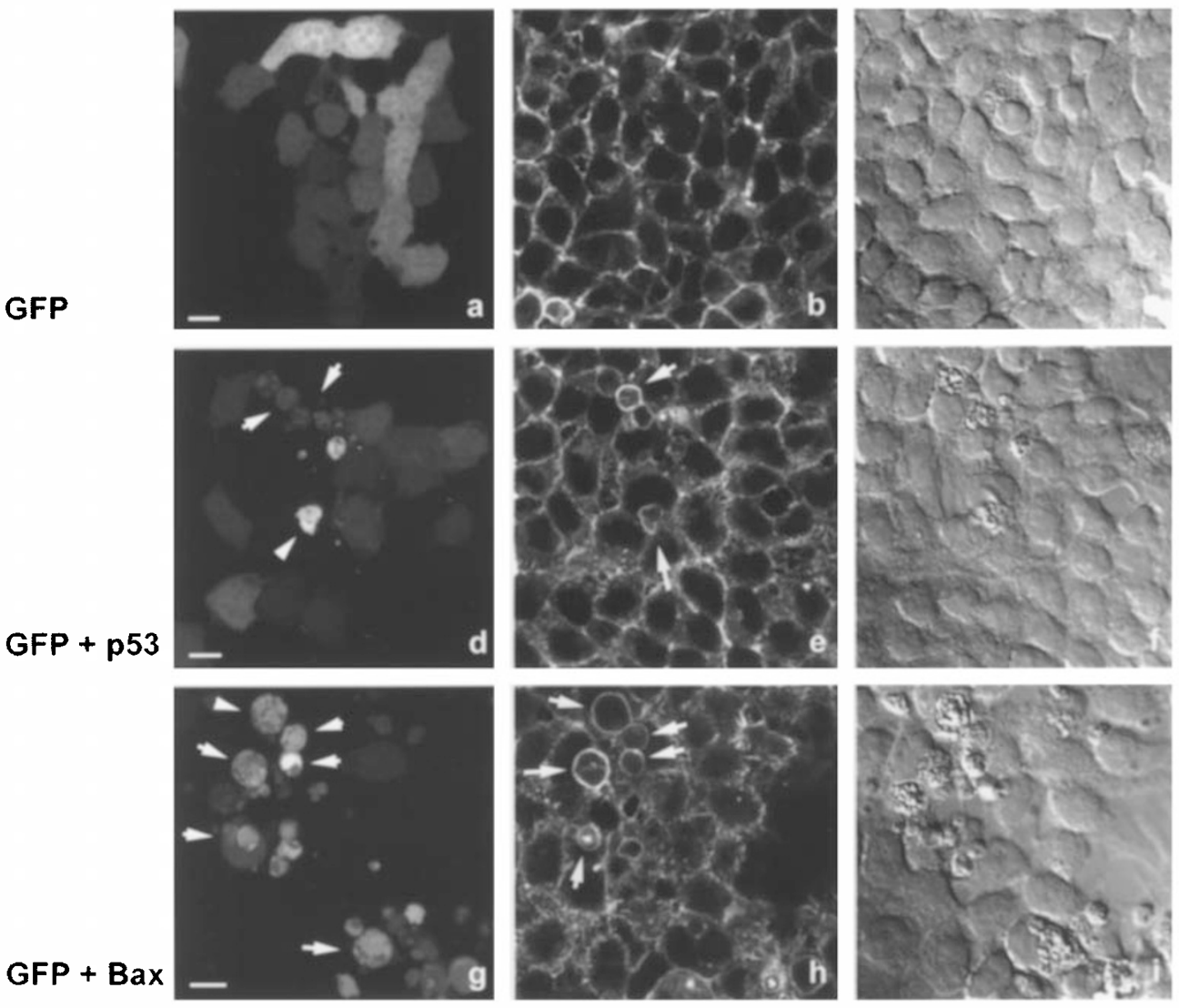

GFP

F-actin

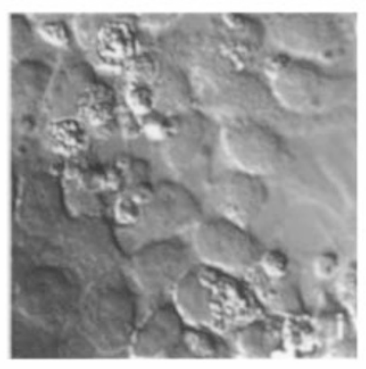

DIC

B

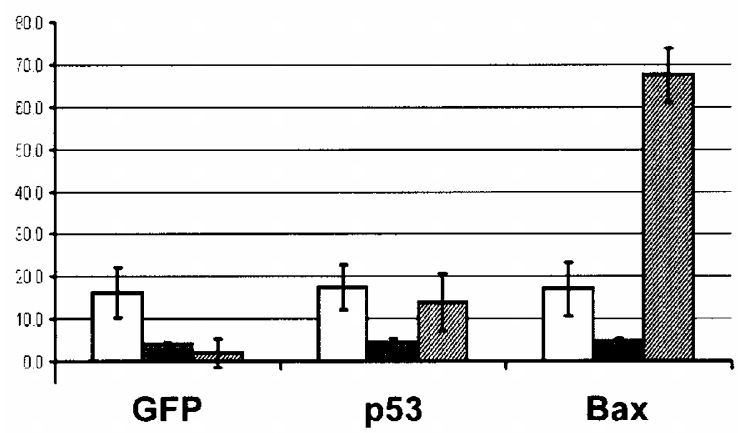

C

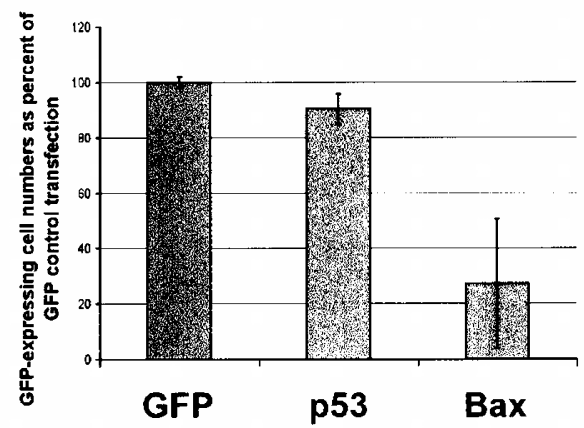

口\% sub G0/G1 cells, 24 h $\square \%$ sub G0/G1 cells, 48 h

Q \% engulfed GFP-expressing cells

Figure 4 p53 and Bax enhance the engulfability of apoptotic 293 cells. 293 cells were transiently transfected with parent vector, or vectors encoding p53, or Bax, and pcDNA3 (see Materials and Methods) and co-transfected with pEGFP-C1 for detection of transfected cells by GFP-coexpression. (A) Confocal micrographs of cells $48 \mathrm{~h}$ post-transfection, fixed in situ, and counterstained with phalloidin-TRITC to visualise F-actin. Arrows depict engulfed, GFP-expressing cells in panels d and $\mathbf{g}$; in panels $\mathbf{e}$ and $\mathbf{h}$ engulfed cells that are encircled by $\mathbf{F}$-actin rings are indicated by arrows. Bars, $10 \mu \mathrm{m}$. (B) Apoptosis and phagocytosis assay of cells, transfected as described above, then $24 \mathrm{~h}$ later mixed with equal numbers of non-transfected 293 cells. Aliquots of cells were analysed for apoptosis by flow cytometry before mixing with non-transfected cells (open bars); and after mixing with non-transfected cells (filled bars; $48 \mathrm{~h}$ post-transfection). Phagocytosis counts are expressed as numbers of engulfed GFP-expressing cells as percentages of total numbers of GFP-expressing cells ( \pm S.E.M.; hatched bars). Several GFPexpressing bodies in the same phagocyte were counted as one phagocytic event. (C) Flow cytometric quantitation of GFP-expressing cells. Numbers of green fluorescent cells in the presence or absence of co-transfected p53 or Bax are expressed as percentage numbers of GFP-expressing cells transfected with pEGFP. $\mathrm{C} 1$ alone ( $48 \mathrm{~h}$ after transfection). Results show mean values of at least six separate experiments $( \pm$ S.E.M.) 


\section{Apoptotic 293 cells are not always efficiently engulfed by neighbouring cells of the same type}

DNA damage induces an increase in transcriptionally active p53 protein levels. ${ }^{42}$ Therefore, to address whether enhancement of engulfability due to p53 overexpression might be simulated by activation of a DNA damage response, we examined engulfment following death induction with DNA damage-dependent and -independent stimuli. Etoposide induces apoptosis as a consequence of DNA damage, ${ }^{43}$ whereas the kinase inhibitor staurosporine induces programmed cell death even in anucleate cells. ${ }^{44} 293$ cells exposed to a semilethal dose of etoposide for $48 \mathrm{~h}$ exhibited a more than 10-fold increase in phagocytes (cells containing one or more phagosomes) compared to controls (Figure 6A, solid bars); despite this, there was a substantial percentage of unengulfed apoptotic cells (approximately $50 \%$ of the total cell population; Figure 6A unfilled bars). Microscopic inspection of etoposide-treated cells prepared for scoring of phagocyte cell numbers, revealed cells containing engulfed apoptotic bodies within phagocytic vacuoles (Figure 6B, panel $b$, indicated by arrow). In case a phagocytic ceiling may have been exceeded, the response to a range of doses of etoposide over a time course was examined but remained essentially the same: phagocytosis failed to keep pace with apoptosis.

Even more strikingly, staurosporine not only consistently revealed unengulfed apoptotic cells (Figure 6A, unfilled bars), there was little or no evidence of phagosomes containing recognisable apoptotic or viable cells (Figure 6A, solid bars); again, this was consistent over a range of doses and time points. Nonetheless, on close microscopic inspection of staurosporine-treated cells, what appeared to be multiple phagocytic vacuoles containing small amounts of cell debris were noted (Figure 6B, panel c, see arrow); again, this was consistently observed at all doses and time points. This observation would be consistent with delayed rather than absent phagocytic engulfment of staurosporinetreated cells; engulfment delay would lead to secondary necrosis in at least a proportion of cells. Engulfment of cells that have undergone secondary necrosis is itself unsurprising given that cell debris arising from necrosis $a b$ initio is also engulfed. ${ }^{6}$

\section{Engulfment remains the same when drug-treated cells are mixed with healthy, untreated cells}

Even in experiments where a substantial percentage of viable cells remained, we were concerned that both etoposide and staurosporine may have non-specifically poisoned the phagocytic capability in the viable cell population. This might conceivably have accounted for engulfment deficiency in drug-treated compared to transfected cell populations where the fraction of viable untransfected cells might have allowed high proficiency engulfment. To address this, we mixed etoposide or staurosporine pretreated, then washed, cells with healthy, untreated 293 cells in equal proportions; under these conditions, free apoptotic cells were still observed and again, only etoposide was associated with phagocytosis of recognisable cells or apoptotic bodies (Figure 6A, hatched bars). Proportions of treated to untreated cells were comparable to ratios of transfected to untransfected cells since mean transfection efficiencies were $32.4 \%( \pm 7.5 \%$ S.E.M.). Thus, apoptosis induced by etoposide and staurosporine is associated with relative engulfment deficiency, albeit to different extents.

The consistently different efficiencies with which etoposide and staurosporine treated cells were engulfed led us to address whether there may be differential expression of cell surface proteins or other moieties, which mediate phagocyte recognition and uptake of the apoptotic cell. We tested a range of inhibitors of cell surface-mediated recognition and engulfment; these included phospho-L-serine (to inhibit a putative PS receptor on the phagocyte), a mixture of sugars (Galactose/Mannose/N-acetylglucosamine) to block competitively carbohydrate moieties on the apoptotic cell, neutralising anti-vitronectin and anti-thrombospondin antibodies, and glibenclamide (an inhibitor of the $A B C$ transporter). None of these potential inhibitors of phagocytosis had a significant effect on etoposide-driven phagocytosis (not shown); a proviso however is that none of these inhibitors is completely effective at blockade of engulfment, even when a particular recognition mechanism is known to predominate. $^{45}$

\section{Cells in the professional phagocyte lineage discriminate between cells triggered to die by different stimuli}

To address whether 293 cells induced to die by etoposide or staurosporine would be differentially engulfed by cells in the professional phagocyte lineage, 293 cells marked with a

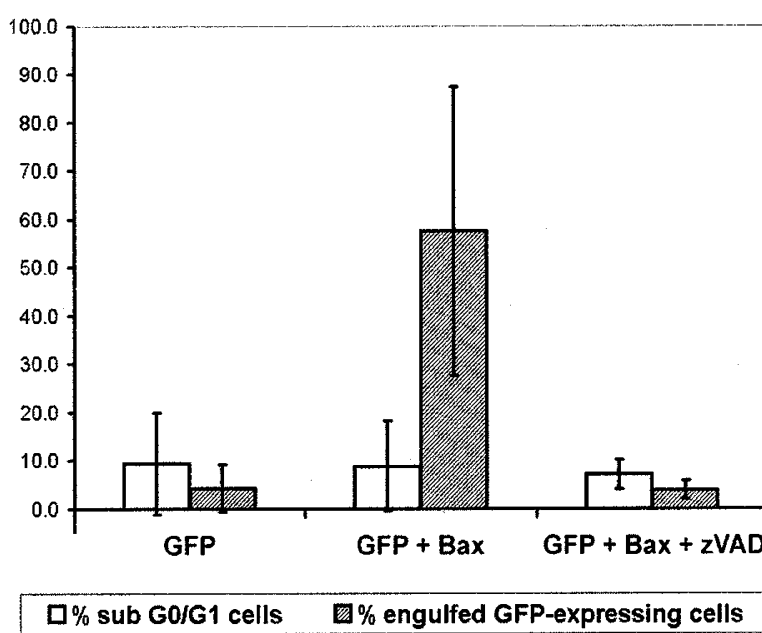

Figure 5 Bax-driven engulfment is caspase-dependent. 293 cells were transfected with parent vector or Bax, and co-transfected with GFP. Cells were incubated in the presence or absence of $100 \mu \mathrm{M}$ of the caspase inhibitor ZVAD-fmk in the medium for $24 \mathrm{~h}$. Assessment of apoptosis (open bars) and phagocytic engulfment (hatched bars) was carried out as described in Figure 4 , except that no mixing with non-transfected cells was performed. Numbers of engulfed GFP-expressing cells are expressed as percentages of total GFPexpressing cells within the same transfection. Mean values from four separate experiments are given ( \pm S.E.M.) 

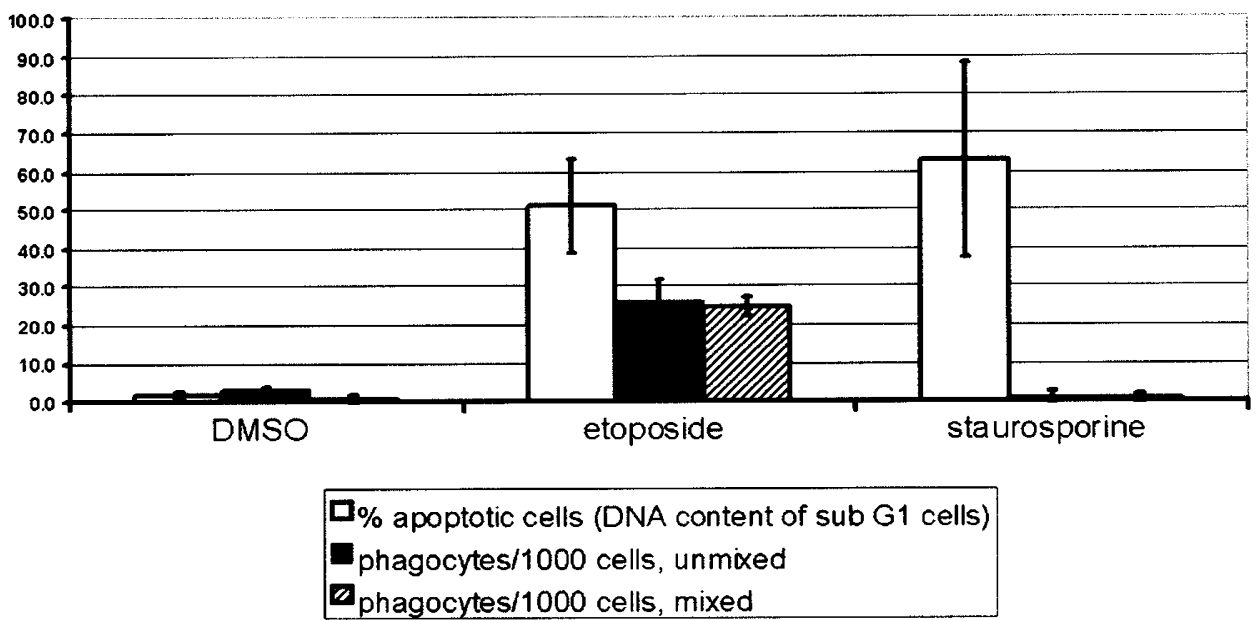

B
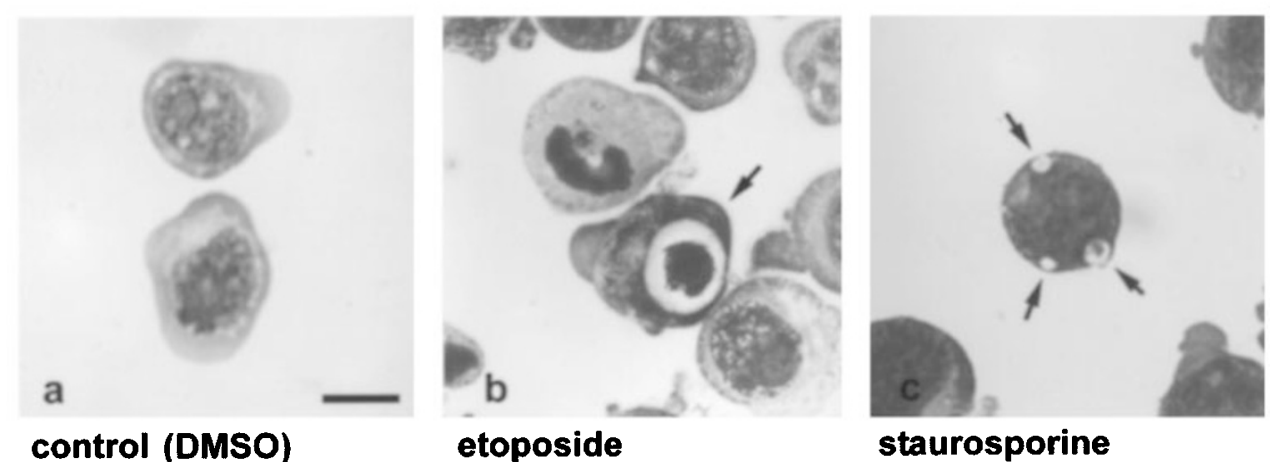

Figure 6 Apoptotic 293 cells are not always efficiently ingested. (A) 293 cells were incubated with $50 \mu$ M etoposide, $100 \mathrm{nM}$ stauroporine, or DMSO (solvent control) for $48 \mathrm{~h}$. Cells were then harvested and processed for apoptosis and phagocytosis assay as described in Materials and Methods. Apoptotic cells with subnormal DNA contents are expressed as a percentage of the total cell population (sample size: $n=20000$; open bars). Mean percentage values from at least three different experiments $( \pm$ S.E.M.) are shown. Phagocyte scores (cells containing one or more phagosomes) were obtained by counting at least 2000 cells per sample in triplicate; numbers of phagocytes are expressed as a fraction of 1000 sample cells. The data represent the mean phagocyte scores from at least four independent experiments ( \pm S.E.M.) after $48 \mathrm{~h}$ treatment (filled bars). For assay of phagocytosis in a cell-mixing experiment (hatched bars) 293 cells were incubated in presence of etoposide or staurosporine for $24 \mathrm{~h}$, trypsinised, washed, then mixed with an equal number of untreated 293 cells, incubated for another $24 \mathrm{~h}$, and processed as described above. (B) Bright field micrographs of 293 cells treated with DMSO (control; panel a), etoposide (panel b), or staurosporine (panel c). Arrowheads in panel $\mathbf{c}$ depict small phagosomes with engulfed debris. Bar, $10 \mu \mathrm{m}$

green cell tracker dye were treated with etoposide or staurosporine such that approximately $50 \%$ of cells were induced to undergo apoptosis (Figure 7, unfilled bars). Then they were presented to healthy THP-1 cells (a monocyte cell line) which were PMA-treated to induce differentiation ${ }^{46}$ and marked in turn with an orange cell tracker dye; engulfment of treated 293 cells by THP-1 cells was assessed $4 \mathrm{~h}$ later. A significantly higher percentage of etoposide-treated 293 cells were engulfed by THP-1 cells, compared to staurosporinetreated 293 cells which largely remained unengulfed (Figure 7 , hatched bars). These data suggest that the etoposidemediated drive to enhanced engulfment originates from the apoptotic cell, that it is not necessarily a homotypic mechanism, and that cells even with an inherently high phagocytic capability can discriminate between cells dying in response to different triggers.

\section{Discussion}

The prevalence of dedicated and stand-by phagocytes and the efficiency with which apoptotic cells are engulfed have understandably failed to incite inquiry into potential links between apoptotic and phagocytic control mechanisms. But fortuitous phagocytic intervention, no matter how efficient, still seems a somewhat inadequate explanation for the fact that in the developing brain, more than half of all neurons that are born, die by apoptosis without any harmful consequences; ${ }^{47}$ in this case phagocytosis must be resoundingly successful in keeping pace with the apoptotic load. On the other hand, apoptosis floridly outstrips engulfment in Fas-mediated hepatic cell death, leading to massive secondary necrosis. ${ }^{7}$ One explanation for these differences might lie in different innate phagocytic capabilities of different tissues. An 
alternative explanation might be that, even within the same tissue or cell type, apoptosis, depending on its trigger, dictates different extents of phagocytic engulfment.

Our data indicate that the trigger to cell death can determine the efficiency with which cells doomed to die are ingested by healthy neighbours or professional phagocytes. Remarkably, when p53 and Bax were transiently overexpressed using 'non-toxic' transfection methods, cells were engulfed so efficiently that evidence of induced apoptotic engagement was confined to cells that had been ingested. However, not all pro-apoptotic stimuli are so efficient at rendering 293 cells recognisable to each other either for homotypic engulfment or to professional phagocytes (THP-1 cells after differentiation induction). Unlike overexpressed p53 and Bax, etoposide and staurosporine treatments were consistently associated with the revelation of 'free' unengulfed apoptotic cells. This was also the case when drug-treated cells were mixed with healthy, untreated cells (and furthermore, proportions of engulfed to unengulfed cells remained the same). Thus, it is extremely unlikely that the relative degree of engulfment proficiency in transfected cell populations compared to drug-treated cells is merely due to the fraction of

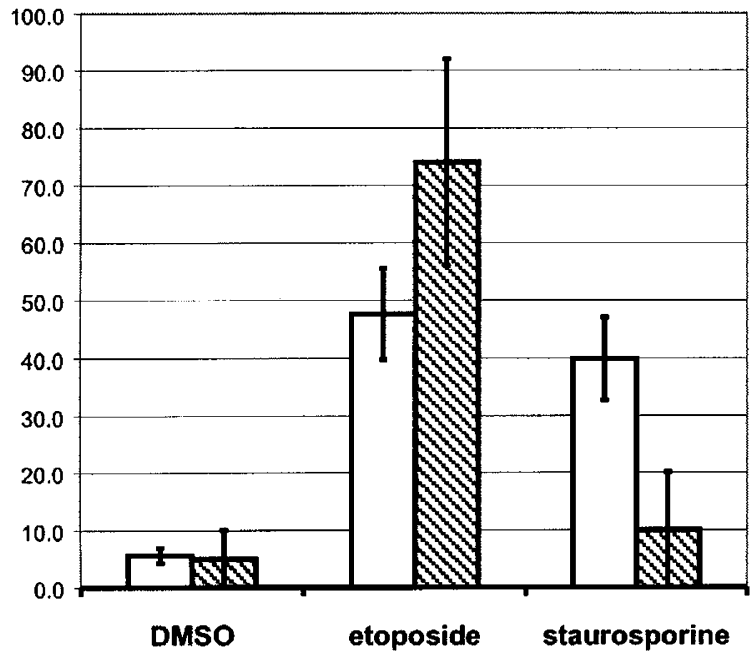

\begin{tabular}{|l|}
\hline$\%$ apoptotic cells (sub G1 \\
DNA content) \\
293 cells engulfed by THP-1 \\
cells/1000
\end{tabular}

Figure 7 Monocytic THP-1 cells discriminate between 293 cells dying by DNA damage-dependent and -independent mechanisms. 293 cells were labelled with $10 \mu \mathrm{M}$ of the permanent green cell dye CMFDA and treated with $50 \mu \mathrm{M}$ etoposide or with $100 \mathrm{nM}$ staurosporine to induce comparable levels of apoptosis. Apoptotic 293 cell populations were then mixed with orange cell dye CMTMR stained THP-1 cells $(1: 1)$ induced to partially differentiate (see Materials and Methods). Mixed cell populations were incubated for $4 \mathrm{~h}$ and then processed for assessment of phagocytosis. Mean values from two different experiments carried out in triplicate $( \pm$ S.E.M.) are expressed as numbers of 293 cells engulfed by THP-1 cells per 1000 cells (sample size: $n=1000$; hatched bars). Parallel samples without cell dye were prepared following the same procedure for assessment of the percentages of apoptotic cells by flow cytometry as described for Figure 1 (sample size: $n=20000$; open bars) untransfected cells (particularly as transfection efficiencies were in excess of $30 \%$ ).

Additional evidence implies that different apoptotic stimuli intrinsically programme the dying cell to be engulfed with differing efficiencies. Cells dying in response to etoposide or staurosporine differed consistently in the efficiency with which they were engulfed. Etoposidetreated cells were engulfed sufficiently early that cells with a typical apoptotic appearance were visible inside phagosomes; but not so early as to prevent the revelation of free apoptotic cells. Staurosporine-treated cells, on the other hand, were consistently delayed in their engulfment (over a range of doses and time points) such that only remnants of cells that appeared to have undergone secondary necrosis were visible within phagosomes; no engulfed apoptotic cells were observed but many unengulfed apoptotic cells were present. This implies that staurosporine-treated cells were programmed to be delayed in their engulfment until a very late stage of the apoptotic programme. Drug-treated cells were also recognised with limited and differential efficiency by professional phagocytes (approximately $8 \%$ of etoposide-treated 293 cells were engulfed by THP-1 cells compared to only $1 \%$ of staurosporine treated cells).

Etoposide induces apoptosis as a result of DNA damage; staurosporine induces programmed cell death, inhibitable by zVAD-fmk, in a wide variety of mammalian cell types. ${ }^{48}$ Since staurosporine does not require the presence of the nucleus to induce death ${ }^{44}$ its mechanism of priming for death is fundamentally different from that of etoposide; but the requirement for caspase activation in execution of the death program is common to both etoposide $^{48}$ and staurosporine ${ }^{49}$ and thus the same core death program is engaged.

How, then, might etoposide and staurosporine, both of which engage caspase-dependent death, differentially regulate engulfment? One possibility is that different initiator caspases, which are similarly inhibited by zVAD$\mathrm{fmk}$, are involved: it is known for example that caspase-8 is activated in response to death receptor signalling whereas caspase- 9 is activated by cytotoxic agents. ${ }^{50}$

An interesting theme to emerge is that cellular stress may also be able to influence the engulfability of apoptotic cells. We noted that when cells were transiently transfected using the calcium phosphate method rather than a less toxic lipid-mediated method, even p53 and Bax consistently induced free apoptotic cells although engulfment (of recognisable cells) was still apparent (data not shown). Furthermore, when RelA (p65), a subunit of $\mathrm{NF}_{\kappa} \mathrm{B}$ which has a pro-apoptotic tendency in 293 cells, was transfected into these cells, we consistently observed the induction of free apoptotic cells with evidence of late phagocytosis only (comparable to staurosporine) (McTavish et al.; data in preparation). It is possible therefore that $\mathrm{NF}_{\kappa} \mathrm{B}$ is a component of cellular stress pathways which may modulate phagocytosis.

In the case of high proficiency engulfment with p53 and Bax, how then might engulfment be so perfectly synchronised with apoptotic signalling that no cells are allowed to enter the apoptotic programme without having been engulfed first? Our data indicate that caspases are required for engulfment, 
which, in the absence of evidence of apoptotic engagement at the point of engulfment, suggests that initiator rather than effector caspases ${ }^{50}$ may be involved in signalling early engulfment. Cells are therefore poised and ready to execute the apoptotic programme at the point of engulfment. Another possibility is that phagolysosomes may actively accelerate the process of apoptotic execution once cells are engulfed.

How might early engulfment be mediated? An early, as yet uncharacterised, signal mediates the tethering of senescent pre-apoptotic neutrophils to macrophages. ${ }^{51}$ Although this tethering signal is early, it is abolished by zVAD-fmk and is therefore downstream from caspase activation, a feature shared by Bax- and p53-dependent engulfment.

Differential exposure of PS by the apoptotic cell, a known signal for engulfment, in response to differential caspase activation was another possibility we considered. Zhuang and co-workers ${ }^{41}$ showed that PS exposure on the apoptotic cell is blocked by zVAD-fmk and therefore lies downstream from caspase activation. As yet, we have no evidence for involvement of PS. Labelling with annexin V was not possible in this cell line due to technical difficulties so we used a functional approach instead. There was no significant inhibitory effect of phospho-L-serine or glycerophosphoryl-L-serine on DNA damage-induced or Baxinduced engulfment (data not shown). Furthermore, engulfment apparently occurred before the surface membrane had become permeable to Hoechst 33342, which is reported to parallel PS exposure. ${ }^{41}$

Although p53- and Bax-mediated engulfment requires caspases, it is possible that the specific priming (possibly tethering) event is upstream from caspase activation; however, engulfment is only carried to fruition (culminates in a successful phagocytic event) once caspases have been activated and the intracellular death program has been engaged. Apoptotic cell membrane changes do occur even before caspase activation. McCarthy et al. ${ }^{48}$ have reported that $\mathrm{zVAD}-\mathrm{fmk}$ does not prevent cell surface 'blebbing' in response to etoposide; nonetheless, 'blebbing' denotes a commitment to die since cells, once they have reached this point, can no longer be rescued from death. It may therefore be that p53- and Baxmediated priming for engulfment is signalled through early membrane changes before caspases have become activated; however, successful engulfment still requires caspase activation.

Zhuang and co-workers ${ }^{41}$ showed that inhibition of mitochondrial function, using the agents antimycin and oligomycin, blocked PS exposure and engulfment, but the intracellular death program proceeded unchecked. Given that Bax is translocated to the mitochondrial membrane during apoptosis ${ }^{52-54}$ we considered whether mitochondrial function was required for Bax-driven engulfment; however, antimycin and oligomycin failed to inhibit Bax-mediated engulfment (data not shown).

To conclude, contrary to previous thinking ${ }^{4,6}$ this study has shown that the trigger to cell death by apoptosis can determine the extent to which dying cells are recognised and removed by phagocytes; apoptotic cells are not necessarily equally marked for safe clearance. In particu- lar, p53 and Bax drive apoptosis that is especially proficient in leading to efficient phagocyte clearance of unwanted cells. This may provide a new approach towards promoting safe clearance of apoptotic cells, which may be beneficial in autoimmune and other disease states.

\section{Materials and Methods}

\section{Cell culture}

293 and Saos2::p53 $3^{\text {teti }}$ clone 13 cells (kindly provided by C Midgeley and D Lane) were grown in DMEM and THP-1 cells in RPMI 1640 (both media from GIBCO Life Technologies, Scotland, and supplemented with 10\% FCS from Helena BioSciences, UK and penicillin/ streptomycin). In addition Saos2::p53 $3^{\text {teti }}$ cells were grown in the presence of $1 \mathrm{mg} / \mathrm{ml}$ G418 (GIBCO Life Technologies, Scotland). THP-1 cells were treated with $40 \mathrm{nM}$ phorbol 12-myristate 13-acetate (PMA) for induction of monocyte maturation ${ }^{46}$ before mixing them with the apoptotic 293 cell population.

\section{Transient transfection}

Cells were transiently transfected using a lipid-based transfection method (Effectene reagent; Qiagen, Germany) following the instructions of the supplier except for the experiment shown in Figure 1 , where the calcium phosphate method was used. ${ }^{55}$ In general, $7 \times 10^{5} 293$ cells per sample were transfected and grown in a standard volume of $2 \mathrm{ml}$ medium per well of a 6 -well plate. For transfection either $1 \mu \mathrm{g}$ of $\mathrm{p} 53$-encoding plasmid or $0.5 \mu \mathrm{g}$ of $\operatorname{pcDNA3/Bax} \beta$ was used. As vector control the appropriate amount of pcDNA3 was transfected. In order to standardise promoter competition effects pcDNA3 was also added to Bax transfections to normalise total DNA amounts. For detection of transfection $1 \mu \mathrm{g}$ of pEGFP-C1 was cotransfected where indicated.

\section{Plasmids and DNA preparation}

pcDNA3 was purchased from Invitrogen (The Netherlands). pcDNA3/ p53 was kindly provided by $\mathrm{K}$ Ryan and $\mathrm{K}$ Vousden and was constructed as described previously. ${ }^{56}$ Two plasmids (pCMVHu9927 and pCMVHu9926) encoding the mutants $\mathrm{p} 53^{\mathrm{H} 175}$ and $\mathrm{p} 53^{\mathrm{W} 248}$ were provided by $C$ Midgeley and $D$ Lane. $1.8 \mathrm{kbp}$ fragments of these plasmids encoding the appropriate p53 mutants were cloned into the $\mathrm{BamHI}$ site of pcDNA3 in order to generate pcDNA3/p53 ${ }^{\mathrm{H} 175}$ and pcDNA3/p53 ${ }^{\text {W248. }}$. A 682 bp EcoRI cDNA fragment encoding cytosolic $\operatorname{Bax} \beta^{57}$ was subcloned into the EcoRI site of pcDNA3. The sequence of the CDNA inserts of all constructs was confirmed by sequencing both DNA strands. All DNA manipulations were carried out using standard techniques. ${ }^{55}$ DNA was prepared using a Plasmid mega kit (Qiagen, Germany). pEGFP-C1 was supplied by Clontech (UK).

\section{Materials}

All chemicals were purchased from Sigma-Aldrich (UK), except for annexin V-FITC (PharMingen, Europe), Effectene transfection reagent (Qiagen, Germany), In situ cell death detection kit/fluorescein (Boehringer, Germany), Benzyloxycarbonyl-valinyl-alanyl-aspartyl(OMe)-fluoromethyl ketone (zVAD-fmk; Calbiochem, UK), 5-chloromethylfluorescein diacetate (CellTracker Green; Molecular Probes, Europe), 5-(and 6)-(((4-chloromethyl)benzoyl)amino)tetramethyl- 
rhodamine (CellTracker Orange; Molecular Probes, Europe), and DPX mountant for microscopy (BDH Merck, UK). Etoposide, staurosporine, ZVAD-fmk, and TRITC-phalloidin were dissolved in DMSO.

\section{Apoptosis assay}

For assessment of apoptosis cells were harvested by trypsinising in the presence of EDTA (0.25\% Trypsin/ 1 mM EDTA in HBSS; GIBCO Life Technologies, Scotland), washed with PBS and fixed with $-20^{\circ} \mathrm{C}$ cold methanol for at least $30 \mathrm{~min}$. Cells were washed with PBS and the final pellet resuspended in PBS containing $100 \mu \mathrm{g} / \mathrm{ml}$ RNase A and $25 \mu \mathrm{g} / \mathrm{ml}$ propidium iodide and incubated for $10 \mathrm{~min}$ at room temperature. DNA content of cells was determined by measuring the intensity of intercalated propidium iodide utilising a FacScan flow cytometer (Becton Dickinson, USA). As two independent parameters of apoptotic changes cell size and light scattering properties of cells were synchronously assessed during flow cytometry. These results showed no significant deviation when compared to results acquired by quantitation of DNA content of cells (data not shown). In order to filter out background noise caused by debris and cell aggregates the threshold function of the forward scatter channel was used (setting: 24) and a gate was set in a plot forward/side scatter to accept apoptotic and normal cell populations only.

\section{Phagocytosis assay}

Cells were trypsinised and washed as described above. Slides were prepared by cytocentrifugation using a Cytospin 3 (Shandon, UK).

For histochemical staining cells were fixed with methanol for $1 \mathrm{~min}$, and then dyed with $0.1 \%$ eosin $G$ and $1 \%$ thiazine for $1 \mathrm{~min}$, respectively. Phagocytes were scored by brightfield microscopy. GFPexpressing cells were assessed for engulfment by fixation with $4 \% \mathrm{p}$ formaldehyde and then analyzed by fluorescence microscopy using a FITC filter set (\#09/ Zeiss, Germany).

\section{TUNEL labelling of fixed cells}

Cells were fixed after cytocentrifugation using $4 \%$ p-formaldehyde and then processed using an In situ cell death detection kit (fluorescein) following the instructions of the supplier (Boehringer, Germany).

\section{F-actin stain of fixed cells}

Cells were grown on slide flasks (\#170920, Nunc International, UK), washed with PBS, fixed with $4 \% \mathrm{p}$-formaldehyde, and permeabilised with $1 \% \mathrm{NP}-40$ for $10 \mathrm{~min}$. F-actin was labelled by incubation with $200 \mathrm{ng} / \mathrm{ml}$ Phalloidin-TRITC conjugate for $1 \mathrm{~h}$ at room temperature. Slides were washed with PBS and analyzed by confocal microscopy.

\section{Microscopy}

Brightfield and fluorescence microscopy was carried out using an Axioplan 2 microscope (Zeiss, Germany) and images were taken with a Nikon N90/Kodak DCS420 digital imaging system. Confocal images were generated by using a Zeiss LSM410 system. Adobe PhotoShop was utilised for image processing.

\section{Acknowledgements}

We would like to thank Carol Midgeley, David Lane and other members of the laboratory for generous provision of the cell line Saos2::p53 ${ }^{\text {teti }}$, p53 expression vectors, and p53 antibodies. Furthermore we thank $\mathrm{K}$ Ryan and $\mathrm{K}$ Vousden for kindly providing us with $\mathrm{pcDNA} 3 / \mathrm{p} 53$, and $\mathrm{A}$ Chen and CB Thompson for the generous gift of psFFVneo-Bax. We are grateful to Simon Brown and Niall McTavish for helpful discussion. This work was funded by the Wellcome Trust grant no. 033790. B Spruce is a Wellcome Senior Research Fellow in Clinical Science.

\section{References}

1. Raff MC (1992) Social controls on cell survival and cell death. Nature 356: 397 400

2. Ishizaki Y, Cheng L, Mudge AW and Raff MC (1995) Programmed cell death by default in embryonic cells, fibroblasts, and cancer cells. Mol. Biol. Cell 6: 14431458

3. Weil M, Jacobson MD, Coles HS, Davies TJ, Gardner RL, Raff KD and Raff MC (1996) Constitutive expression of the machinery for programmed cell death. J. Cell Biol. 133: 1053-1059

4. Savill J (1997) Recognition and phagocytosis of cells undergoing apoptosis. Br. Med. Bull. 53: 491-508

5. Platt N, da Silva R and Gordon S (1998) Recognizing death: the phagocytosis of apoptotic cells. Trends Cell Biol. 8: 365-372

6. Wyllie AH, Kerr JFR and Currie AR (1980) Cell death: the significance of apoptosis. Int. Rev. Cytol. 68: 251-306

7. Ogasawara J, Watanabe-Fukunaga R, Adachi M, Matsuzawa A, Kasugai T, Kitamura Y, Itoh N, Suda T and Nagata S (1993) Lethal effect of the anti-Fas antibody in mice. Nature 364: 806-809

8. Ellis RE, Jacobson DM and Horvitz HR (1991) Genes required for the engulfment of cell corpses during programmed cell death in Caenorhabditis elegans. Genetics 129: 70-94

9. Wu Y-C and Horvitz R (1998) C. elegans phagocytosis and cell-migration protein CED-5 is similar to human DOCK180. Nature 392: $501-504$

10. Liu QA and Hengartner MO (1998) Candidate adaptor protein CED-6 promotes the engulfment of apoptotic cells in C. elegans. Cell 93: 961-972

11. Wu Y-C and Horvitz R (1998) The C. elegans cell corpse engulfment gene ced-7 encodes a protein similar to $A B C$ transporters. Cell 93: 951-960

12. Gobé GC and Axelson RA (1987) Genesis of renal tubular atrophy in experimental hydronephrosis in the rat. Role of apoptosis. Lab. Invest. 56: $273-282$

13. Dini L, Lentini A, Diez GD, Rocha M, Falasca L, Serafino L and Vidal-Vanaclocha F (1995) Phagocytosis of apoptotic bodies by liver endothelial cells. J. Cell Sci. 108: $967-973$

14. Hess KL, TudorK-SRS, Johnson JD, Osati-Ashtiani F, Askew DS and Cook-Mills JM (1997) Human and murine high endothelial venule cells phagocytose apoptotic leukocytes. Exp. Cell Res. 236: 404-411

15. Savill J, Smith J, Ren Y, Sarraf C, Abbott F and Rees AJ (1992) Glomerula mesangial cells and inflammatory macrophages ingest neutrophils undergoing apoptosis. Kidney Int. 42: 924-936

16. Baker AJ, Mooney A, Hughes J, Lombardi D, Johnson RJ and Savill J (1994) Mesangial cell apoptosis: the major mechanism for resolution of glomerular hypercellularity in experimental mesangial proliferative nephritis. J. Clin. Invest. 94: $2105-2116$

17. Hall SE, Savill J, Henson PM and Haslett C (1994) Apoptotic neutrophils are phagocytosed by fibroblasts with participation of the fibroblast vitronectin receptor and involvement of a mannose/fucose-specific lectin. J. Immunol. 153: 3218-3227

18. Duvall E, Wyllie AH and Morris RG (1985) Macrophage recognition of cells undergoing programmed cell death. Immunology 56: 351-358

19. Fadok VA, Voelker DR, Campbell PA, Cohen JJ, Bratton DL and Henson PM (1992) Exposure of phosphatidylserine on the surface of apoptotic lymphocytes triggers specific recognition and removal by macrophages. J. Immunol. 148: 2207-2216

20. Verhoeven B, Schlegel RA and Williamson P (1995) Mechanisms of phosphatidylserine exposure, a phagocyte recognition signal, on apoptotic $T$ lymphocytes. J. Exp. Med. 182: 1597-1601

21. Marguet D, Luciani M-F, Moynault A, Williamson P and Chimini G (1999) Engulfment of apoptotic cells involves the redistribution of membrane phosphatidylserine on phagocyte and prey. Nature Cell Biol. 1: 454-456 
22. Flora PK and Gregory CD (1995) Recognition pathways in the interaction of macrophages with apoptotic B cells. In Leukocyte typing: white cell differentiation antigens, Schlossman SF, Boumsell L and Gilks W, eds (Oxford: Oxford University Press) p 1675

23. Moffat OD, Devitt A, Bell ED, Simmons DL and Gregory CD (1999) Macrophage recognition of ICAM-3 on apoptotic leukocytes. J. Immunol. 162: 6800-6810

24. Savill J, Dransfield I, Hogg N and Haslett C (1990) Vitronectin receptor-mediated phagocytosis of cells undergoing apoptosis. Nature 343: 170-173

25. Rubartelli A, Poggi A and Zocchi MR (1997) The selective engulfment of apoptotic bodies by dendritic cells is mediated by the $\alpha_{v} \beta_{3}$ integrin and requires intracellular and extracellular calcium. Eur. J. Immunol. 27: 1893-1900

26. Savill J, Hogg N, Ren Y and Haslett C (1992) Thrombospondin cooperates with CD36 and the vitronectin receptor in macrophage recognition of neutrophils undergoing apoptosis. J. Clin. Invest. 90: 1513-1522

27. Ren Y, Silverstein RL, Allen J and Savill J (1995) CD36 gene transfer confers capacity for phagocytosis of cells undergoing apoptosis. J. Exp. Med. 181: 1857- 1862

28. Platt N, SuzukiH, Kurihara Y, Kodama Tand Gordon S(1996)Role for the class A macrophage scavenger receptor in the phagocytosis of apoptotic thymocytes in vitro. Proc. Natl. Acad. Sci. USA 93: 12456-12460

29. Luciani M-F and Chimini $G$ (1996) The ATP binding cassette transporter ABC1 is required for the engulfment of corpses generated by apoptotic cell death. EMBO J. 15: $226-236$

30. Moynault A, Luciani M-F and Chimini G (1998) ABC1, the mammalian homologue of the engulfment gene ced-7, is required during phagocytosis of both necrotic and apoptotic cells. Biochem. Soc. Transactions 26: 629-635

31. Hamon Y, Broccardo C, Chambenoit O, Luciani M-F, Toti F, Chaslin S, Freyssinet J-M, Devaux PF, McNeish J, Marguet D and Chimini G (2000) ABC1 promotes engulfment of apoptotic cells and transbilayer redistribution of phosphatidylserine. Nature Cell Biol. 2: 399-406

32. Devitt A, Moffat OD, Raykundalia C, Capra JD, Simmons DL and Gregory CD (1998) Human CD14 mediates recognition and phagocytosis of apoptotic cells. Nature 392: 505-509

33. Korb LC and Ahearn JM (1997) C1q binds directly and specifically to surface blebs of apoptotic human keratinocytes. J. Immunol. 158: 4525-4528

34. Botto M, Dell'Agnola C, Bygrave AE, Thompson EM, Cook HT, Petry F, Loos M Pandolfi PP and Walport MJ (1998) Homozygous C1q deficiency causes glomerulonephritis associated with multiple apoptotic bodies. Nature Genet. 19: 56-59

35. Fadok VA, Bratton DL, Rose DM, Pearson A, Ezekewitz RAB and Henderson PM (2000) A receptor for phosphatidylserine-specific clearance of apoptotic cells. Nature 405: $85-90$

36. Debbas and White $E$ (1993) Wild-type $p 53$ mediates apoptosis by $E 1 A$, which is inhibited by E1B. Genes Dev. 7: 546-554

37. Pan G, O'Rourke K and Dixit VM (1998) Caspase-9, Bcl- $X_{L}$ and Apaf-1 form a ternary complex. J. Biol. Chem. 273: 5841-5845

38. Han J, Wallen HD, Nunez G and White E (1998) E1B 19,000-molecular-weight protein interacts with and inhibits CED-4-dependent, FLICE-mediated apoptosis. Mol. Cell. Biol. 18: 6052-6062

39. Jürgensmeier JM, Zhihua X, Deveraux Q, Ellerby L, Bredesen D and Reed JC (1998) Bax directly induces release of cytochrome c from isolated mitochondria. Proc. Natl. Acad. Sci. USA 95: 4997-5002
40. Desagher S, Osen Sand A, Nichols A, Eskes R, Montessuit S, Lauper S, Maundrell K, Antonsson B and Martinou JC (1999) J. Cell Biol. 144: 891-901

41. Zhuang J, Ren Y, Snowden RT, Zhu H, Gogvadze V, Savill J and Cohen GM (1998) Dissociation of phagocyte recognition of cells undergoing apoptosis from other features of the apoptotic program. J. Biol. Chem. 273: 15628-15632

42. Vogelstein B, Lane D and Levine A (2000) Surfing the p53 network. Nature 408: $307-310$

43. van Maanen JMS, Retèl J, de Vries J and Pinedo HM (1988) Mechanisms of action of antitumour drug etoposide: a review. J. Natl. Cancer Inst. 80: 15261533

44. Jacobson MD, Burne JF and Raff MC (1994) Programmed cell death and Bcl-2 protection in the absence of a nucleus. EMBO J. 13: 1899-1910

45. Fadok VA, Savill J, Haslett C, Doherty DE, Bratton DL, Campbell PA and Henson PM (1992) Different populations of macrophages use either the vitronectin receptor or the phosphatidylserine receptor to recognise and remove apoptotic cells. J. Immunol. 149: 4029-4035

46. Tsuchiya S, Kobayashi Y, Goto Y, Okumura H, Nakae S, Konno T and Keiya T (1982) Induction of maturation in cultured human monocytic leukemia cells by a phorbol diester. Cancer Res. 42: 1530-1536

47. Raff MC, Barres BA, Burne JF, Coles HS, Ishizaki Y and Jacobson MD (1993) Programmed cell death and the control of cell survival: lessons from the nervous system. Science 262: $695-700$

48. McCarthy NJ, Whyte MKB, Gilbert CS and Evans GI (1997) Inhibition of Ced-3/ ICE-related proteases does not prevent cell death induced by oncogenes, DNA damage, or the Bcl-2 homologue Bak. J. Cell Biol. 136: 215-227

49. Jacobson MD, Weil Mand Raff MC (1996) Role of Ced-3/ICE-family proteases in staurosporine-induced programmed cell death. J. Cell Biol. 133: 1041-1051

50. Thornberry NA and Lazebnik Y (1998) Caspases: enemies within. Science 281: $1312-1316$

51. Knepper-Nicolai B, Savill J and Brown S (1998) Constitutive apoptosis in human neutrophils requires synergy between calpains and the proteasome downstream of caspases. J. Biol. Chem. 273: 30530-30536

52. Gross A, Jockel J, Wei MC and Korsmeyer SJ (1998) Enforced dimerization of Bax results in its translocation, mitochondrial dysfunction and apoptosis. EMBO J. $17: 3878-3885$

53. Nechushtan A, Smith CL, Hsu Y-T and Youle RJ (1999) Conformation of the Bax C-terminus regulates subcellular location and cell death. EMBO J. 18: $2330-$ 2341

54. Porter AG (1999) Protein translocation in apoptosis. Trends Cell Biol. 9: $394-$ 401

55. Ausubel FA, Brent R, Kingston RE, Moore DD, Seidman JG, Smith JA and Struhl K, eds (1998) Current protocols in molecular biology (New York: John Wiley \& Sons)

56. Ryan KM and Vousden KH (1998) Characterization of structural p53 mutants, which show selective defects in apoptosis but not cell cycle, arrest. Mol. Cell. Biol. 18: $3692-3698$

57. Oltvai ZN, Milliman CL and Korsmeyer J (1993) Bcl-2 heterodimerizes in vivo with a conserved homolog, Bax, that accelerates programmed cell death. Cell 74 : $609-619$ 